\title{
Questão agrária e campesinato: teoria e paradigma no contexto da corrente marxista clássica
}

\author{
Pedro Henrique Vanzo \\ Recebido em março de 2021 \\ Aceito em junho de 2021
}

\section{RESUMO}

Qual o sentido e as tendências do desenvolvimento capitalista na agricultura, e qual o destino do camponês frente ao modo de produção capitalista? Ou ainda: quem é, afinal, o camponês? Esse artigo propõe fomentar o debate em torno desses questionamentos através da análise de como os clássicos marxistas colocaram a questão agrária e sobre o campesinato em pauta, tendo como primeira referência o próprio Marx, em seguida Lênin e Kautsky. Depois, ao trazer as contribuições de Alexander Chayanov, enquanto representante de uma corrente teórica contraposta aos marxistas clássicos, o artigo propõe evidenciar o debate que, a partir dos anos finais do século XIX, vem dominando os estudos agrários no que diz respeito as tendências da agricultura e do campesinato em relação aos processos de desenvolvimento do modo de produção capitalista. $O$ trabalho se estrutura a partir de uma revisão de literatura sobre os clássicos em questão, e finaliza tecendo leituras sob a perspectiva contemporânea dos estudos agrários e rurais, em particular no contexto brasileiro. Pode servir, assim, como instrumento e bagagem teórica daquele que procura compreender como vem se estruturando a dinâmica teórica e analítica da categoria social do campesinato e as mudanças agrárias em curso num contexto de modernização capitalista.

Palavras-chave: Questão agrária; Campesinato; Marxismo; Alexander Chayanov.

\section{Agrarian question and peasant: theory and paradigm in the context of the classical marxist current}

\begin{abstract}
What is the meaning and tendencies of capitalist development in agriculture, and what is the fate of the peasant in the face of the capitalist mode of production? Or again: who is, after all, the peasant? This article proposes to boost the debate around these questions through the analysis of how the classic Marxists put the agrarian question and the peasantry on the agenda, having Marx himself as the first reference, followed by Lenin and Kautsky. Afterwards, by bringing the contributions of Alexander Chayanov, as a representative of a theoretical current opposed to the classical Marxists, the article proposes to highlight the debate that, from the final years of the 19th century onwards, has dominated agrarian studies with regard to tendencies in agriculture and peasantry in relation to the development processes of the capitalist mode of production. The work is structured by a literature review on the classics in question, and concludes by indicating possible readings from the contemporary perspective of agrarian and rural studies, particularly in the Brazilian context. It can thus serve as an instrument and theoretical background for those seeking to understand how the theoretical and analytical dynamics of
\end{abstract}

\footnotetext{
${ }^{1}$ Mestrando do Programa de Pós-Graduação de Sociologia (PPGSocio) da Universidade Federal do Paraná (UFPR), Curitiba, Paraná, Brasil. Bolsista da Coordenação de Aperfeiçoamento de Pessoal de Nível Superior (CAPES). E-mail: pedrohvanzo@gmail.com.
} 
the social category of the peasantry and the agrarian changes underway in a context of capitalist modernization have been structuring.

Keywords: Agrarian question; Peasantry; Marxism; Alexander Chayanov.

A questão agrária e o campesinato, como afirma José Paulo Netto (1982), se tornam fenômenos relevantes que passam a ser estudados com maior notoriedade nas últimas décadas do século XIX (com destaque pra última década deste século). As análises que Karl Marx (2017a, 2017b) realizou em sua grande obra O Capital sobre o camponês e a questão rural em detrimento dos processos de desenvolvimento do capitalismo, foi um grande marco teórico para construção posterior de estudos relacionados a esses temas.

Vai ser assim no interior do Partido Social Democrata Alemão (SPD), que a questão agrária vai, pouco a pouco, ganhando maior destaque e importância em relação às análises sobre o modo de produção capitalista. Dentre alguns teóricos, emerge Karl Kautsky (grande leitor e estudioso de Marx) que vai elaborar A Questão Agrária (1899), uma importante obra sobre as tendências das mudanças agrárias no contexto de capitalismo em desenvolvimento. Em condições distintas, debates similares eram elaborados na Rússia sobre os processos de desenvolvimento do capitalismo em relação as mudanças agrárias em curso. Assim, no mesmo ano que Kautsky lançou seu livro, Vladimir Ilyich Ulianov (Lênin), outro assíduo leitor e estudioso das obras de Marx, também lança uma obra de peso sobre a questão agrária: O Desenvolvimento do Capitalismo na Rússia (1899). Com o passar dos anos, Marx, Kautsky e Lênin se tornam importantes referências teóricas sobre o campesinato e as questões agrárias em relação aos processos de desenvolvimento do modo de produção capitalista, influenciando gerações de pesquisadores e provocando importantes debates em torno desses temas.

Contudo, o paradigma do qual se estuda o desenvolvimento do capitalismo na agricultura, cuja matriz são os trabalhos clássicos (marxistas) citados acima, "vem-se mostrando cada vez menos capaz de dar conta dos fenômenos contemporâneos decisivos" (ABRAMOVAY, 1990, p. IV). De acordo com Ricardo Abramovay (1990), há certa dificuldade para a compreensão das questões agrárias contemporâneas por causa das ambiguidades com que a noção de unidade familiar de produção camponesa tem 
sido tratada, sendo que, nesse paradigma, foi muito custoso responder a seguinte questão: o que é o camponês? Por isso, afirma ainda Abramovay que uma teoria sobre o campesinato e sobre a produção familiar na agricultura (suas tendências e suas funções no desenvolvimento capitalista), não existiu de fato na corrente marxista clássica, inclusive pode-se encontrar uma abordagem com um profundo ceticismo em relação à essa categoria social. É preciso, portanto, deixar claro que foi difícil encontrar uma definição precisa sobre o camponês na corrente marxista, isso porque - embora o campesinato esteja presente nessa corrente teórica - foi sempre retratado por ela subsumido às categorias explicativas do modo de produção capitalista.

Apesar de sua importância analítica e teórica, as discussões sobre as questões agrárias e sobre o campesinato não se limitaram apenas aos marxistas. Assim será, de certa forma, contra essa perspectiva clássica que irá emergir estudos e teorias, como por exemplo a de Alexander Chayanov, que elaborou também importante obra sobre a questão agrária e o campesinato na contemporaneidade dos clássicos marxistas, que é a A Organização da Unidade Econômica Camponesa, publicada no ano de 1925. Destaca-se que Chayanov não foi um autor que procurou simplesmente repudiar o marxismo clássico, mas sim acabou se esforçando em elaborar uma teoria dos sistemas econômicos não-capitalistas (que, dentre eles, destaca-se a economia camponesa), e que vai, dessa maneira, divergir da própria corrente teórica marxista. Para ele, a economia camponesa foi considerada um objeto de um conhecimento racional e positivo, e assim procurou demonstrar suas leis de funcionamento e existência enquanto uma necessidade social (ABRAMOVAY, 1990). Essa necessidade será investigada por Chayanov no interior mesmo no próprio "organismo" camponês (mais especificamente, na unidade de produção familiar camponesa).

Assim, Chayanov procurou investigar justamente aquilo que na visão dos marxistas parecia um contra senso, ou seja, buscou uma definição de campesinato cuja a base é construída pela própria família camponesa, e assim verificou as leis e determinações que essa estrutura familiar impõe sobre o próprio comportamento econômico camponês. Conforme afirma Abramovay (1990), há, portanto, um sentido e um compromisso político explícito na obra de Chayanov em evidenciar a unidade e a identidade camponesa: trata-se de um setor da sociedade que possui determinada 
substância que procura pautar um processo autônomo de desenvolvimento social, e de que na luta por essa ideia de desenvolvimento e emancipação, está o esforço em legitimar que sua posição na estrutura social seja respeitada e valorizada. Dessa forma, enquanto uma contracorrente da teoria marxista clássica, Chayanov não apenas reconheceu a existência do camponês independente dos processos de desenvolvimento do modo de produção capitalista, como deixou claro que o campesinato se desenvolve e reproduz sob outra lógica e outro sistema econômico que não o capitalista.

Dessa forma, o artigo tem por objetivo tratar dessa polêmica que dominou o século XX (SILVA e STOLCKE, 1981) - e que se estende ainda em nosso século -, sobre o desenvolvimento capitalista na agricultura e sobre a questão do destino dos camponeses frente a esses processos de desenvolvimento. Em resumo, procura-se através deste trabalho fomentar o debate para pensarmos as seguintes questões: qual o sentido e as tendências do desenvolvimento capitalista na agricultura, e qual o destino do camponês frente ao modo de produção capitalista? Para isso, será elaborada uma leitura e sistematização da questão agrária e sobre o campesinato tendo como referência os escritos e obras dos próprios clássicos marxistas (Marx, Lênin e Kautsky), além da obra de Alexander Chayanov $(1974 ; 1981)$, enquanto representante de outra corrente teórica e analítica sobre o tema. O objetivo então é verificar como a questão agrária e o campesinato foi colocada por esses autores citados através de seus próprios escritos, na intenção não apenas de fomentar as discussões sobre os temas, mas de oferecer direcionamentos teóricos para aquele que se interessa em investigar questões e fenômenos relacionados aos questionamentos levantados por este trabalho.

\section{Karl Marx: a acumulação primitiva do capital e os processos de expropriação/exploração dos camponeses}

Foi em sua grande obra $O$ Capital (2017a; 2017b) que Marx dedicou grande parte para analisar com maior detalhamento os conteúdos relacionados às questões agrárias e rurais. Foi através do fenômeno que chamou de pré-história do capitalismo, ou seja, a acumulação primitiva do capital (o momento de transição do modo de produção feudal para o modo de produção capitalista, desde o século XIV ao XIX), que 
Marx se debruçou em compreender as mudanças agrárias em consequências dos processos de desenvolvimento do capital, analisando as transformações nas organizações de vida camponesa, na agricultura, na propriedade e na renda fundiária.

Nas palavras do próprio Marx, então, a acumulação primitiva não foi $o$ resultado do modo de produção capitalista, mas sim seu ponto de partida, isto é, o processo em que a estrutura econômica da sociedade capitalista surge em decorrência da estrutura econômica da sociedade feudal; em outras palavras, foi a dissolução do feudalismo que possibilitou a liberação dos elementos necessários para emergência do capitalismo. A acumulação primitiva foi então, segundo Marx, o fenômeno que acabou por transformar o dinheiro e as mercadorias em capital, além de ser, principalmente, o processo histórico de separação entre produtor e meio de produção. Assim, o processo que:

[...] cria a relação capitalista não pode ser senão o processo de separação entre o trabalhador e a propriedade das condições de realização de seu trabalho, processo que, por um lado, transforma em capital os meios sociais de subsistência e de produção, e por outro, converte os produtores diretos em trabalhadores assalariados (MARX, 2017a, p. 786).

De acordo com Marx, uma visão historiográfica burguesa concebeu esse processo histórico que transformou os produtores em trabalhadores assalariados como uma espécie de "libertação" dessas pessoas da servidão e da coação corporativa do feudalismo. Porém, Marx apresenta outra visão discorrendo que na verdade essa libertação dos trabalhadores nada mais foi que o roubo - através de muito "sangue e violência" - de todos os seus meios de produção e reprodução, bem como de todas as suas garantias de existência. Assim, o processo da acumulação primitiva corresponde à época das transformações que serviram de alavanca para a formação do capitalismo, e que essas alavancas foram, acima de tudo, o momento em que as "grandes massas humanas" são despojadas súbita e violentamente de seus meios de subsistência e lançados no mercado de trabalho como proletários "livres". Dessa maneira, afirma Marx que foi a expropriação da terra que antes pertencia ao produtor rural, o camponês, a base de todo processo inicial de desenvolvimento do modo de produção capitalista. Tal método conquistou a possibilidade do campo da "agricultura 
capitalista", onde a incorporação do solo ao capital acabou criando para a indústria urbana emergente a oferta necessária de um proletário agora "livre", fruto dos processos de expropriação que sofreram em decorrência do desenvolvimento do capitalismo.

Contudo, esses trabalhadores camponeses expulsos e expropriados violentamente de suas terras, não puderam ser absorvidos pela manufatura emergente à serviço do capital, e muitos simplesmente não conseguiam se ajustar a disciplina que essa nova situação os obrigou a passar. Assim, essa população rural (agora expulsos e expropriados de suas terras) "viu-se obrigada a se submeter, por meio de leis grotescas e terroristas, e por força de açoites, ferro em brasa e torturas, a uma disciplina necessária ao sistema de trabalho assalariado" (MARX, 2017a, p. 8o8). Assim resume-se que, para Marx, a acumulação primitiva foi forjada em processos intermitentes e sempre renovados de expropriação e expulsão da população rural, que foi fornecendo à indústria urbana massas cada vez maiores de proletários. Nesse contexto, então, o camponês tem agora de adquirir, por meio de salários e em servidão ao seu "novo senhor", o capitalista industrial, o valor necessário aos seus meios alimentares, ou seja, sua própria subsistência. Sua sobrevivência agora passou a depender do capitalista industrial e de seu próprio salário.

Marx (2017a) então acaba por analisar principalmente a situação específica do camponês (trabalhador agrícola) inglês. Irá tratar do retrocesso que esses trabalhadores rurais ingleses tiveram em relação ao processo antagônico da produção e acumulação capitalista. Afirma ele que, apesar da agricultura moderna datar - na Inglaterra - em meados do século XVIII (momento de maior análise de Marx em relação a questão agrária e do camponês inglês), os processos de transformação fundiária e agrícola do modo de produção capitalista são muito anteriores (remontando aqui a análise que fez em relação à transição do mundo feudal para o capitalista). Afirma Marx ao analisar a situação desses trabalhadores rurais ingleses do século XVIII, principalmente nas décadas de 1770 e 1780 , que tanto as questões que dizem respeito a suas condições alimentares, moradia e habitação, quanto as de dignidade pessoal, diversão, entre outros, constituem ideais que nunca mais seriam alcançados novamente. Dito de outra forma, Marx concebe o desenvolvimento do 
capitalismo como um fenômeno que, de forma inevitável, arruína com os processos de produção e reprodução de vida desses trabalhadores rurais ingleses; na medida em que o capitalismo avança, tende a acabar com toda forma de produção camponesa, inevitavelmente. Nesse contexto, analisa Marx que a situação do camponês era então transformada à pura miséria, a mais brutal dos sofrimentos, sendo que "de todos os animais mantidos pelos arrendatários, o trabalhador, o instrumentum vocale [instrumento falante], tornou-se a partir de então o mais extenuado, o pior alimentado e o que recebe o tratamento mais brutal" (MARX, 2017a, p. 748, grifos do autor).

Já outra análise importante que Marx realizou e que nos auxilia para refletirmos sobre as questões agrárias, foi o desenvolvimento da maquinaria e da grande indústria. Relata ele que a finalidade da maquinaria foi sempre baratear mercadorias e encurtar a parte da jornada de trabalho que os trabalhadores necessitam para si mesmos, a fim de prolongar a outra parte de sua jornada, que ele dá gratuitamente ao capitalista (nas palavras do próprio Marx, a maquinaria é meio para a produção de mais-valor). Além disso, afirma ele que a transformação dos meios de trabalho (meios de produção) constitui o ponto de partida da grande indústria, e essa transformação assume a sua forma mais desenvolvida nos sistemas articulados das máquinas nas fábricas. Disso aponta algumas consequências imediatas, como por exemplo o aumento do trabalho feminino e infantil - como muito bem demonstrou Engels (2010) em A Situação da Classe Trabalhadora na Inglaterra -, como também o prolongamento da jornada de trabalho e a intensificação do trabalho (na intenção do aumento cada vez maior de produtividade). E será, portanto, na esfera da agricultura que Marx diz que a grande indústria (com seu novo e poderoso maquinário emergente) acabou atuando de maneira mais revolucionária, "ao liquidar o baluarte da velha sociedade, o "camponês", substituindo-o pelo trabalhador assalariado" (MARX, 2017a, p. 572). É na agricultura, portanto, que as transformações capitalistas nos processos de produção tornam o meio de trabalho um meio de subjugação, de exploração e de empobrecimento do trabalhador. Além de ser um processo que "saqueia" o trabalhador, saqueia e explora também a própria terra.

De acordo com Marx, o capitalismo, então, se apodera e domina a agricultura. Como o modo de produção capitalista em geral baseia-se na expropriação dos 
trabalhadores das condições de trabalho, "na agricultura ele se baseia na expropriação dos trabalhadores rurais da terra e sua subordinação a um capitalista, que explora a agricultura visando o lucro" (MARX, 2017b, p. 675). Com isso, chega à análise da propriedade e da renda fundiária da terra. O autor coloca que a propriedade fundiária capitalista se baseia no monopólio de certas pessoas capitalistas/proprietárias que detêm porções definidas do globo terrestre como esferas exclusivas de sua vontade privada, com exclusão das massas de trabalhadores. Com isso, o monopólio da propriedade da terra é uma premissa histórica da qual Marx afirma ser a base constante do modo de produção capitalista. Assim, formula as condições prévias de funcionamento do modo de produção capitalista, da seguinte maneira: os verdadeiros cultivadores do solo são os assalariados (os antigos camponeses), que são empregados pelo capitalista (o arrendatário), que só se dedica a agricultura como campo de exploração específico para a acumulação de riquezas (lucro). O capitalista-arrendatário paga ao proprietário fundiário (o proprietário da terra por ele explorada, que muitas vezes pode ser representado pela mesma pessoa) em prazos e valores determinados fixados em contratos. Esse valor pago é o que Marx trata, portanto, como a renda fundiária, e afirma que é essa renda, então, a forma na qual se realiza economicamente a propriedade fundiária. Com isso, temos aqui, reunidas e confrontadas, as três classes que Marx considerou como as classes constituintes do marco da sociedade moderna: o trabalhador assalariado, o capitalista industrial e o proprietário fundiário (MARX, 2017a).

Contudo, afirma Marx, ainda ao tratar sobre a renda fundiária, que o aumento do valor da terra é idêntico à desvalorização do trabalho, ou seja, o alto nível do preço da terra é igual ao baixo nível do preço do trabalho. Dessa forma, a renda fundiária é concebida estando diretamente relacionada ao preço do trabalho, influenciando diretamente nos baixos salários e nas péssimas condições nas quais se encontram os trabalhadores rurais (como exposto nos parágrafos anteriores). A apropriação da renda é a forma econômica na qual se realiza a propriedade fundiária; por sua vez, a renda da terra pressupõe uma propriedade da terra, daí a expropriação e exploração dos camponeses e também dos processos de concentração de terras em domínios de poucas pessoas. 
Por fim, conclui então que a transformação das sociedades agrícolas feudais em capitalistas ocorreu tendo como verdadeira importância o rápido desenvolvimento do capital, por meio da rápida expropriação dos produtores independentes (camponeses) e a transformação destes em trabalhadores assalariados, e por meio da acumulação e concentração fortemente aceleradas dos capitais, isto é, por meio da criação das condições do modo de produção capitalista. Então, vai afirmar Marx (2017a) que toda produção de mais-valor e, portanto, também todo desenvolvimento do capital, de acordo com sua base natural, repousa sobre a produtividade do trabalho agrícola. Está dada, portanto, a importância que a questão agrária assume nos estudos de Marx em relação ao processo de desenvolvimento do capitalismo, e como este autor analisou o camponês em função do processo histórico de desenvolvimento desse novo modo de produção em emergência.

\section{Vladimir Lênin: os processos de diferenciação agrária e a desintegração do camponês}

Lênin, principalmente em sua obra $O$ desenvolvimento do capitalismo na Rússia (1982), realizou importante e detalhada análise sobre os processos de desenvolvimento do capitalismo naquele país em relação às mudanças agrárias em curso. Assim, nessa obra o autor se debruça em analisar e criticar o movimento que, a partir da década de 1860, passa a emergir na Rússia, conhecido mais tarde por populismo.

Conforme discorre Netto (1982), os populistas, então, eram conhecidos na Rússia por repelir o capitalismo ocidental, e com isso esperavam que o país fosse capaz de superar o capitalismo através da experiência dos $\mathrm{mir}^{2}{ }^{2}$ transferindo-se diretamente para o socialismo agrário. Os populistas eram convencidos que a economia rural e as instituições camponesas eram poderosos antídotos contra o capitalismo. Assim,

\footnotetext{
${ }^{2}$ Mir eram comunidades rurais na Rússia, onde a terra, por exemplo, era um bem compartilhado por todos em que nela moravam. Essas comunidades, existentes até meados do século XX, serviram de inspiração aos populistas Russos para superação do modo de produção capitalista em emergência naquele país.
} 
pretendiam preservar essas instituições camponesas e a economia rural, para evitar o estágio ocidental do capitalismo, tal como os processos ocorridos na Europa. Contudo, pouco a pouco, conforme Lênin irá demonstrar, as transformações econômicas e sociais da Rússia foram claramente se inclinando para a via capitalista, e é com isso, portanto, que ele irá desferir suas maiores críticas ao populismo, analisando as mudanças agrárias na Rússia, tendo como pano de fundo o aprofundado estudo da obra do Capital de Marx.

Assim, morando na província de Samara na última década do século XIX, Lênin se direciona em analisar a questão agrária na Rússia, e vai procurar conhecer a realidade camponesa através de investigações concretas, realizando levantamentos e análises de dados empíricos e estatísticos sobre essas populações rurais. Irá concluir e demonstrar posteriormente que os camponeses foram levados a ruína, e que esses processos só ocorreram porque foram necessários para o pleno desenvolvimento do capitalismo no país, onde os processos crescentes de industrialização foram liberando as massas camponesas para a formação do proletariado (similar ao que o próprio Marx observou na Inglaterra). A crítica ao populismo então é feita por Lênin através de demonstrações da possibilidade concreta do capitalismo se desenvolver na Rússia, e pela desintegração do campesinato através da formação de três segmentos diferenciados e opostos no mundo rural russo: os camponeses ricos, os camponeses médios e os camponeses pobres (LÊNIN, 1982).

Similar ao que Marx fez em analisar a transição do modo de produção feudal para o modo de produção capitalista (aquilo que ele chamou de acumulação primitiva), Lênin também analisará a passagem da agricultura da Corveia (feudalismo) para a agricultura capitalista, ou seja, a passagem da economia camponesa para a latifundiária. O período da corveia, como vai analisar Lênin, foi o momento em que as terras eram divididas em duas partes: as terras senhoriais e as terras camponesas. As terras camponesas eram pedaços de terra concedidas aos camponeses, que cultivavam os meios de sua própria subsistência com seus próprios instrumentos (meios de produção). Do outro lado, o trabalho excedente representava o cultivo do latifúndio (dos senhores), realizados com os mesmos meios de produção dos camponeses. Desse modo, "o lote camponês era, nesse sistema, uma forma de salário em espécie (para 
empregarmos a linguagem de hoje), ou um meio de assegurar a mão-de-obra para o latifúndio" (LÊNIN, 1982, p. 123).

Define Lênin, então, sobre a economia baseada na corveia: ela (economia) não existia simplesmente para assegurar os meios de subsistência dos camponeses, mas sim para assegurar mão de obra para o latifúndio feudal. Esse sistema se garantia por uma "coação extraeconômica", ou seja, o camponês dependia pessoalmente do senhor, pois, sem essa dependência, não teria a relação necessária de servidão para a construção da base de estruturação do sistema feudal. Contudo, o fim da corveia foi momento em que Lênin discorre que houve a abolição da servidão, onde ocorreu o fim da economia natural dos feudos, onde o caráter "fechado" e autossuficiente do feudo veio a ruína, e o poder do latifundiário sobre os camponeses também. É um momento em que Lênin trata como a transição entre as economias, onde foi necessário, em primeiro lugar, certa "libertação" dos camponeses e sua habituação para um novo tipo de trabalho, o trabalho assalariado (ou seja, a formação do proletariado, como também o próprio Marx discorreu). Essa libertação dos camponeses da qual fala Lênin, portanto, é o que ele caracterizou e tratou como a desintegração do campesinato, que é representada pela decadência do sistema de pagamento em trabalho (que era, portanto, o sistema econômico da corveia), para a formação do sistema de pagamento através de salários. Isso fez com que se formasse um processo de decomposição dos pequenos agricultores em patrões e/ou operários agrícolas, através de processos de diferenciação e oposição entre eles.

Dessa forma, o autor irá tratar então desses processos de diferenciação entre os camponeses em decorrência dos processos de desenvolvimento do capitalismo, que assim ficou conhecido como a formação de três grupos sociais do campesinato russo: os camponeses ricos, os médios e os pobres. Discorre Lênin que quanto mais a produção mercantil penetra a agricultura (portanto, quanto mais o capitalismo se desenvolve no meio rural), mais se agudiza também a concorrência entre os agricultores, as disputas pela terra e as lutas pela independência econômica, e assim leva a perda total do campesinato médio e pobre pela burguesia camponesa. Dessa maneira, Lênin buscou analisar dados estatísticos produzidos sobre os Zemtovs (províncias russas), e afirma o seguinte: "deles, resulta inquestionável a conclusão de 
que o campesinato está em total desintegração, com o pleno domínio da burguesia camponesa" (LÊNIN, 1982, p. 46). Discorre ele que quem se desintegra nesse processo é o camponês pobre e o médio, porque o rico (burguesia camponesa) se torna uma outra coisa: um capitalista, e não mais um "camponês". Desse processo então resulta que, de um lado, tem-se os ricos, praticantes da grande agricultura e pecuária capitalista, e do outro os camponeses médios e pobres, aos quais não restou outra coisa do que a venda de sua força de trabalho. Conforme afirma o autor, a comunidade camponesa russa não se forma antagônica ao capitalismo - como propunha os populistas -, mas sim constitui a sua base mais profunda e sólida (igualmente ao resultado que Marx obteve ao concluir as análises sobre o desenvolvimento do capitalismo na Inglaterra).

A desintegração do campesinato então, de acordo com Lênin, é a destruição radical do antigo campesinato patriarcal e a criação de novos tipos de população rural (agora subordinados e subsumidos ao capital - os ricos, médios e pobres). O campesinato antigo não simplesmente se diferencia, mas sim "deixa de existir, se destrói, é inteiramente substituído por novos tipos de população rural, que constituem a base de uma sociedade dominada pela economia mercantil e pela produção capitalista" (LÊNIN, 1982, p. 114). Essa desintegração, portanto, é a criação de dois extremos: o da burguesia rural (camponeses ricos, proprietários de estabelecimentos e empresas industriais/comerciais) e o proletariado rural (os camponeses pobres, que não possuem outra coisa senão sua própria força de trabalho para vender). No meio disso está o camponês médio, que está no esforço constante de se tornar rico: contudo só poucos conseguem, e quando fracassam (o que é normal acontecer), acabam tendo também apenas a força de trabalho para vender, e assim ocupam juntos o lugar de camponês pobre.

Por fim, ainda através de dados empíricos e estatísticos, Lênin observa o crescente emprego de máquinas na agricultura russa, e traz conclusões no que diz respeito as consequências desses processos (aumento do trabalho infantil e feminino, aumento da intensidade do trabalho e o prolongamento da jornada de trabalho, etc.). Contudo, reconhece que o crescimento da produção agrícola de tipo técnico foi de enorme importância para o desenvolvimento do capitalismo na Rússia. Com isso, vai relacionar constantemente esses processos de desenvolvimento do capitalismo que 
incide sobre a desintegração do campesinato, como um processo que o autor tratou de "descamponização", ou seja, os processos de transformação e desintegração do campesinato. Afirma, então, que o crescimento da agricultura comercial (capitalista) acompanha a criação de um mercado interno para o capitalismo, e com isso a tendência de se introduzir na "cena mundial" através da ampliação infinita da produção comercial agrícola. Em síntese, vai afirmar Lênin então que o capitalismo segue, portanto, a tendência de dominar a agricultura, isto é, a agricultura, as mudanças agrárias e o campesinato submetidos aos interesses do capitalismo e de seu desenvolvimento histórico.

\section{Karl Kautsky: a destruição do camponês e a relação entre a grande e a pequena exploração agrícola}

Karl Kautsky (1972a, 1972b), como já informado na introdução, foi outro estudioso das questões agrárias que posteriormente se tornou um referencial teórico clássico sobre o tema. Relata o autor que o interesse pelas questões agrárias começa a aparecer em seus estudos já na década de 1870. À época, Marx vinha se tornando a base teórica do movimento socialista mundial, e com a publicação e repercussão do terceiro volume de sua grande obra d'O Capital, a questão agrária vinha ganhando cada vez mais destaque.

Começa Kautsky por tratar do campesinato na idade média, contexto no qual essa categoria social fazia parte de uma sociedade que se bastava inteiramente a si própria, através da produção de sua própria subsistência, a construção própria de utensílios domésticos e de sua moradia, como também de suas próprias vestimentas, entre outros. Era uma sociedade camponesa abastada, segura e confiante no futuro, como relata o autor. Porém, discorre que tudo começou a mudar a partir do momento de maior atuação da indústria e do comércio urbano, mexendo nas estruturas camponesas no campo, provocando alterações na estrutura da divisão do trabalho no seio da comunidade camponesa. Diz que o desenvolvimento da indústria e do comércio produziu nas cidades novas necessidades que, com os instrumentos novos e aperfeiçoados, penetrava no campo de maneira tanto mais rápida e tanto mais 
"irresistível" quanto mais ativas se tornavam as relações entre a cidade e o campo, necessidades essas que a simples indústria camponesa não podia mais satisfazer. Assim, o começo da indústria urbana, ainda na idade média, foi o início da dissolução da indústria e economia camponesa: "só a indústria capitalista tem uma tão grande superioridade que elimina rapidamente a indústria doméstica do camponês" (KAUTSKY, 1972a, p. 26). Dito de outra forma, quanto mais a indústria urbana avança, mais rapidamente acontecem também as transformações nos modos de vida dos camponeses, afirmando (como Marx) que a mesma evolução que, por um lado, produz a necessidade de operários assalariados cria, por outro, esses próprios operários. Isto é, a revolução capitalista produz os processos de proletarização dos camponeses, reduzindo suas famílias e lançando no mercado de trabalho os excedentes de filhos e filhas dessas comunidades como a nova mão de obra necessária para o modo de produção capitalista.

Com isso, afirma Kautsky que a antiga sociedade da família camponesa é então substituída pelas "grandes explorações", sendo que o antagonismo de classes passa a penetrar nas comunidades rurais e destrói a antiga "harmonia" da comunidade camponesa. O autor coloca que "o desenvolvimento do modo de produção capitalista apenas na cidade já basta para transformar completamente a existência do camponês" (KAUTSKY, 1972a, p. 31), mesmo antes ainda de se formar o principal antagonismo entre a pequena e a grande exploração. Dessa maneira, Kautsky vai falar da destruição do camponês devido a entrada das pressões exteriores à comunidade camponesa, que antes bastava a si própria e era inteiramente independente. As transformações mais profundas se mostram logo de início nas próprias condições de vida dos camponeses, como por exemplo sua alimentação: Kautsky fala que o camponês se torna agora (com o desenvolvimento do capitalismo) um faminto, pois com as novas estruturas se formando, que retiram dele o seu caráter de subsistência e autossuficiência, falta-lhe comida, e quando tem, é de má qualidade.

Por boa parte de seus estudos, Kautsky também disserta sobre as revoluções ocorridas nos métodos e equipamentos/máquinas na agricultura, da crescente dependência da agricultura ao comércio, da agricultura se desenvolvendo enquanto ciência e da própria renda fundiária (análises muito similares ao que Marx observou na 
Inglaterra e Lênin na Rússia). Com isso, chega por fim a principal análise de sua obra, que é sobre a relação entre a grande e a pequena exploração, e trata logo de início da superioridade técnica da grande exploração: "quanto mais o capitalismo se desenvolve na agricultura, mais aumenta a diferença qualitativa entre a técnica da grande exploração e da pequena" (KAUTSKY, 1972a, p. 129). Além dos meios técnicos, a grande exploração também é superior no que diz respeito a economia e otimização de recursos, tirando melhores proveitos, por exemplo, da divisão do trabalho dentro da agricultura. Por outro lado, analisa também as desvantagens da pequena exploração: o excesso de trabalho e a insuficiência do consumo dos camponeses. Vai afirmar que só um "partidário fanático" poderia ser ainda adepto da pequena exploração, visto que sua maior consequência é a exploração do próprio camponês (pelas más condições de vida a que são submetidos). Sendo assim, o autor disserta que a pequena exploração "é um fenômeno econômico do passado", e que mostra um verdadeiro "obstáculo ao progresso econômico" (KAUTSKY, 1972a, p. 156).

Com isso, Kautsky irá concluir que existe uma forte tendência de a pequena exploração desaparecer, ainda que não houvesse desaparecido por completo. Isso porque a grande exploração nunca está sozinha, pois depende de "braços" para o trabalho, sendo que esses braços são oriundos sempre dos proletários da própria pequena exploração. Assim, vai afirmar que onde quer que a grande exploração tenda a eliminar a pequena, existirão sempre certos conservadores e grandes proprietários fundiários que irão se esforçar por aumentar o número de pequenas explorações, por medidas de ordem política e privada (para manutenção da "ordem" da grande exploração). Irá concluir, portanto, que a pequena exploração não deixa de existir por completo, e que também não representa mais uma competição com a grande, mas que passam então a coexistir. Apesar de não deixar de existir, a vida e a existência do camponês e da pequena exploração, segundo as análises de Kautsky, são condições necessárias para manutenção e desenvolvimento do capital através da atuação da grande exploração. Dessa forma, a industrialização capitalista da agricultura prende o pequeno agricultor (camponês) à fábrica, "transformando-o inteiramente num escravo do capital industrial, segundo as necessidades do qual ele tem que explorar a terra. É esta a salvação que a indústria agrícola traz ao camponês" (KAUTSKY, 1972b, p. 145). 


\section{Alexander Chayanov: a unidade de produção familiar camponesa}

Conforme relata Silva e Stolcke (1981), Alexander Chayanov foi o maior expoente da última geração de populistas russos (populistas estes que tanto Lênin criticou em seus trabalhos) que se dedicou aos estudos agrários, sendo que suas análises recuperam ainda muitos elementos dos chamados "marxistas legais" dos anos 1890-1910. Contudo, em contrapartida propõe um corpo teórico não marxista para a análise das organizações camponesas. Desde o início do século XX o autor já vem postulando o pressuposto que a economia camponesa não é tipicamente capitalista, e afirma, portanto, que é um fenômeno em si mesmo, e que para estudá-lo é necessário elaborar conceitos específicos. Esse populismo agrícola que Chayanov defendia, contra os que consideravam a organização da produção camponesa como uma "fase inferior"

do desenvolvimento da agricultura capitalista, vai posteriormente lhe custar a liberdade e consequentemente a própria vida. Porém o seu legado se perpetuou, e sua obra repercutiu positivamente nos estudos agrários e sobre o campesinato.

Chayanov (1974) propôs elaborar um novo trabalho sobre a unidade econômica camponesa, dizendo que se deve olhar para os debates e teorias anteriores (as marxistas, principalmente), e pautar um novo e renovado método de trabalho. Afirma que nas teorias marxistas, então, o estudo da exploração camponesa era elaborado do ponto de vista do desenvolvimento econômico nacional, e por isso mesmo irá propor elaborar uma teoria particular sobre a unidade econômica camponesa. Assim, a originalidade dos estudos de Chayanov foi então conceber, primeiramente, o camponês não como simples trabalhador assalariado do capital, muito menos como um agricultor capitalista. Dessa forma, se propõe a não tratar a economia camponesa pelo viés do desenvolvimento nacional, e assim se direcionou a investigar a própria unidade familiar de trabalho camponês, o que vai permitir a ele, então, diferenciar essas unidades das demais estruturas econômicas vigentes em sua época, e tratar ao mesmo tempo de sua coexistência com essas outras estruturas econômicas. Ao propor isso, é inevitável, como diz Chayanov, "comezar nuestra investigación com un análisis exhaustivo de la constituición y de las leyes que 
gobiernan la composición del sujeto de esta unidad: la familia que la dirige" (CHAYANOV, 1974, p. 47).

Para Chayanov, não se trata, portanto, de compreender o destino da unidade econômica camponesa (o que muitos - principalmente os marxistas - tentaram propor), nem mesmo de sua concepção histórica e nacional, mas sim compreender "que és la unidad económica campesina desde un punto de vista organizativo ¿Cuál es la morfologia de este aparato productivo?" (CHAYANOV, 1974, p. 36). Afirma, dessa maneira, que é totalmente certo que a exploração rural não é homogênea, e que, inclusive, é representada ainda por numerosas unidades semiproletárias e semicapitalistas. Com isso, se propõe a estudar com detalhes a família mesma em seu desenvolvimento biológico como uma cooperativa de unidades de trabalho e de consumo, tentando compreender as motivações para o trabalho entre os membros da família, assim como a produção e outros elementos que determinam o grau de autoexploração da força de trabalho. Essa auto-exploração da qual fala o autor, se refere a um equilíbrio entre a satisfação da demanda familiar e a própria penosidade do trabalho, ou seja, o nível de força de trabalho empregado pela família é regulado diretamente pelas necessidades dessa unidade familiar, que, segundo Chayanov, deve se utilizar do mercado e das condições naturais da produção como forma de proporcionar equilíbrio interno e níveis mais elevados de bem estar para a unidade familiar camponesa.

Chayanov muito bem observou em seus estudos que, na moderna teoria da economia nacional (aí incluída principalmente a corrente marxista clássica), foi costumeiro pensar que todos os fenômenos econômicos eram de domínio exclusivo dos termos cunhados pela economia capitalista, ou seja, "todos os demais tipos (não capitalistas) de vida econômica são vistos como insignificantes, ou em extinção; no mínimo considera-se que não tem influência sobre as questões básicas da economia moderna e não apresentam, portanto, interesse teórico" (CHAYANOV, 1981, p. 133). Assim, reconhecendo uma multiplicidade de sistemas econômicos, discorre Chayanov que, para cada sistema (sociedade) econômica diferente, deve-se construir um sistema econômico correspondente às suas características particulares. Por isso, irá tratar o autor então da economia natural (camponesa) enquanto fenômeno peculiar/particular 
que, de um lado, evidencia a exigência de satisfação das necessidades de cada unidade (familiar) de produção, e de outro, é também uma unidade de consumo.

No que diz respeito a análise do camponês e sua forma de organização de vida individual e coletiva, relata Chayanov que as categorias econômicas capitalistas são inadequadas para sua análise e investigação. Dado que não existe necessariamente a categoria de "salários" na organização de vida camponesa, são inaplicáveis os conceitos e fórmulas do trabalho assalariado, do lucro, da mais-valia, da acumulação, etc., isso porque é a própria família (equipada com meios de produção) que emprega a própria força de trabalho no cultivo da terra, recebendo como resultado de um ano de trabalho, por exemplo, certa quantidade de bens necessários à sua produção e reprodução familiar. Mesmo assim, Chayanov não torna homogênea as unidades econômicas familiares camponesas e admite que podem variar segundo a situação de mercado na qual se encontram e a localização da unidade relativa a esses mercados, como também a própria disponibilidade dos meios de produção, o tamanho e a composição da família, a qualidade da terra, etc.

Outra característica fundamental é que Chayanov reforça a todo momento que a estrutura de exploração familiar camponesa, a intensidade do cultivo e suas formas organizativas dependem sempre de fenômenos internos (ao contrário da corrente marxista que concebeu esses fenômenos dependentes de fatores externos à unidade familiar), como por exemplo o tamanho da família trabalhadora, a extensão da terra utilizável, a extensão das necessidades, entre outros. Outro fator ainda apontado é que o padrão de vida tradicional das unidades familiares camponesas é mantido e afirmado pelos costumes e hábitos, que determinam juntos as exigências de consumo das famílias, e por consequência a aplicação de sua força de trabalho.

Chayanov analisou com muito detalhe a atividade econômica da família camponesa individual, verificando principalmente os mecanismos de equilíbrio interno da família, e pensando posteriormente também onde se localiza a família camponesa na estrutura econômica nacional e suas relações com essa economia. Em oposição à homogeneização do rural subsumido às categorias econômicas nacionais, Chayanov relata que quando se compara alguns dados e estimativas dos séculos XVII e XVIII, se comprova que a heterogeneidade do rural não é característica exclusiva de sua época, 
mas sim também se evidenciam em períodos históricos anteriores. Por isso, diz que o caráter histórico da heterogeneidade da unidade de produção familiar camponesa deriva da própria natureza de sua exploração, e não é algo ligado a história recente (capitalismo). Por fim, nos lembra novamente sobre os riscos de conceber a própria Economia enquanto ciência que se ocupa somente das estruturas e sistemas capitalistas, e de como isso impossibilita a compreensão de outros sistemas econômicos não-capitalistas (como os camponeses, por exemplo).

Assim, destaca o autor que significativos "blocos" de unidades camponesas de trabalho familiar estão disseminados na economia capitalista mundial, dizendo ainda existir formações econômicas que lembram formas não capitalistas de economia. Dessa forma, Chayanov não simplesmente homogeneizou as diferenças entre economia capitalista versus as não capitalistas, mas sim falou de vários tipos de economias que coexistem. Assim, discorreu que o futuro da teoria econômica "não reside na construção de uma única teoria universal da vida econômica, mas em conceber vários sistemas teóricos, adequados ao elenco de ordens econômicas presentes e passadas, que revelem as formas de sua coexistência e evolução" (CHAYANOV, 1981, p. 163). Assim se estruturou seus estudos no que diz respeito às questões agrárias e do campesinato de sua época, através dessa concepção heterogênea de economia da qual irá se opor, diretamente, à corrente marxista clássica. Consequentemente, foi responsável por inaugurar uma nova corrente teórica sobre o campesinato, principalmente sobre as unidades familiares de produção camponesa, e que posteriormente ganhou importância suficiente para não apenas confrontar as literaturas clássicas já existentes, como também para se tornar uma outra corrente clássica dos estudos agrários mundiais.

\section{Do debate clássico ao rural e as ruralidades no Brasil contemporâneo}

O campesinato no Brasil, a partir das décadas de 1980 e 1990 - momento que se passou a superar, em certa medida, o debate clássico em torno dessa classe social e seu possível desaparecimento frente aos processos de desenvolvimento do modo de produção capitalista -, passou a ser representado historicamente por uma maneira 
singular de civilização e de cultura. É evidente que os camponeses e agricultores familiares brasileiros em questão não mais representam uma reprodução clássica e "tradicional" do campesinato, tal como as sociedades pré-capitalistas, mas nem por isso se deslocaram de sua "condição camponesa" (PLOEG, 2008, p. 39) de existência. Os processos de transformação do campesinato não são simplesmente sua transição de um espaço "isolado" para outro "englobante", nem sua inserção integral na economia e sociedade moderna, mas sim representam processos de rupturas e continuidades (WANDERLEY, 2004) em relação a suas formas de produção e reprodução da vida em decorrência dos processos de transformação ocasionados pelo modelo da modernização capitalista. Evidencia-se, dessa maneira, que a imposição do modelo empresarial de tipo industrial na agricultura, não gerou formas sociais rurais de produção únicas e homogeneizadas, mas sim configurações heterogêneas de um mundo rural marcado pela atuação de diversos atores que, apesar de serem representados no momento histórico de um mundo moderno (capitalista) em questão, preservam também suas tradições e seus movimentos de adaptação a esse mundo. Nesse contexto (últimas décadas do século $\mathrm{XX}$ ) é que a noção de ruralidade (BRANDENBURG, 2018; WANDERLEY, 2009; CARNEIRO, 2012) emerge enquanto categoria analítica e teórica de um rural marcado pela heterogeneidade de formas de vida, e fundamentalmente pela capacidade de adaptação e resistência do campesinato frente aos novos modelos industriais e modernos de agricultura.

A crítica à modernização capitalista da agricultura vem se colocando em diversos países e contextos por atores que acabam por assumir, então, uma condição de vida camponesa em resposta às contradições desse modelo moderno/capitalista em desenvolvimento. Assim emerge a visão sobre o mundo rural, de um lado, como integrado ao conjunto da sociedade brasileira, não mais "isolado", e de outro como um local que mantém certas particularidades históricas e sociais enquanto realidade própria. Um rural emergente enquanto um espaço físico diferenciado e "enquanto um lugar de vida, isto é, lugar onde se vive (particularidades do modo de vida e referência "identitária") e lugar onde se vê e vive o mundo (a cidadania do homem rural e sua inserção na sociedade nacional)" (WANDERLEY, 2001, p. 32). É uma visão que acaba por supor então um lugar onde se têm formas particulares de vida e de trabalho, não 
simplesmente como um lugar de investimento ou reservas de valores (orientações englobantes do modelo capitalista).

A diversificação (heterogeneidade) do rural tem se colocado enquanto palco de fatores de dinamismo e como fonte de conflitos a respeito do que é o rural hoje em dia, quem são seus atores e quais os seus diferentes usos e características principais. $\mathrm{O}$ compromisso, portanto, de compreender o rural como espaço diversificado de vida é além de concebê-lo enquanto um espaço singular com reivindicações próprias -, inserilo como protagonista nos programas políticos de desenvolvimento e assumir uma posição reparadora no que diz respeito aos processos da modernização que o rural e as agriculturas vêm enfrentando de forma mais acentuada e desigual desde os últimos dois séculos (BERNSTEIN, 2011), que acabou marginalizando a existência do camponês e do agricultor familiar nos processos políticos participativos das sociedades modernas, e em específico da sociedade brasileira.

\section{Considerações Finais}

Na literatura clássica sobre a questão agrária e o campesinato (tendo aqui como principal referência as teorias marxistas clássicas), o camponês só pôde ser definido pela "tragédia de seu destino social" (ABRAMOVAY, 1990, p. VIII), ou seja, foi analisado tendo em perspectiva a sua extinção em decorrência dos processos de desenvolvimento do capitalismo. Na medida que o capitalismo avançava em seus processos de industrialização, o camponês tenderia inevitavelmente a ser expropriado e a desaparecer (MARX, 2017a; 2017b), ser desintegrado (LÊNIN, 1982) ou destruído (KAUTSKY, 1972a; 1972b) pelos processos de diferenciação entre os produtores rurais (ou o camponês se tornaria um capitalista proprietário de meios de produção, ou se tornaria um simples trabalhador assalariado, e, portanto, um proletário) ou em relação a sua incapacidade de concorrer com as grandes empresas agrícolas emergentes. Porém, como destaca ainda Abramovay, os clássicos marxistas acabaram por refletir muito mais as suas próprias condições em que viveram do que simplesmente deram conta de elaborar uma teoria universal a respeito da questão agrária e sobre o campesinato. 
Chayanov, por sua vez, inaugura uma nova corrente teórica que vai influenciar fortemente os estudos rurais e agrários na contemporaneidade, assumindo de imediato um contraponto à visão marxista clássica. É através da nova corrente teórica chayanoviana que inúmeros estudos rurais na atualidade se direcionam para compreender o mundo rural e as mudanças agrárias em curso, levando em consideração a importância e preeminência do campesinato enquanto categoria social responsável pela estruturação de um universo em constante conflito e contradição devido aos processos de desenvolvimento do modo de produção capitalista.

Os métodos da modernização capitalista (principalmente aqueles ligados ao setor agrícola, desde suas origens e se acentuando a partir da segunda metade do século XX) que pretendem se tornar dominantes em escala global, pressupõe certa homogeneização da vida no que diz respeito às formas de desenvolvimento social (PLOEG, 2008; BERNSTEIN, 2011). Como bem colocado pela corrente marxista clássica, esses processos de modernização capitalista tendem a homogeneizar as categorias sociais rurais em detrimento do desenvolvimento das sociedades urbanas, ou seja, o mundo rural tende a se modernizar e a refletir as estruturas sociais postuladas pelas sociedades urbano-industriais capitalistas. De acordo com quem defende estritamente essa visão, o camponês inevitavelmente desaparecerá, dando lugar ao agricultor capitalista ou ao simples trabalhador rural assalariado (proletário). Em contraponto a essa visão homogeneizadora da modernização capitalista, a corrente teórica neochayanoviana tem categorizado o universo do rural (em especial o rural brasileiro), enquanto um local heterogêneo de produção e reprodução da vida, onde se encontram estruturas sociais particulares (e peculiares) que estruturam seus mundos a partir das adaptações realizadas frente aos processos de desenvolvimento difundidos pela modernização capitalista, não excluindo, é claro, os efeitos que tal modernização provocou (e continua a provocar) nesse mundo rural.

Evidente, portanto, que essas correntes teóricas são contrapostas no que diz respeito aos estudos teóricos em relação ao mundo rural e as mudanças agrárias em curso. O campesinato, por sua vez, constitui-se hoje enquanto categoria social em constante conflito e contradição explicitada pelas correntes teóricas aqui apresentadas, sendo considerado ora uma categoria social existente, ora desaparecida ou em 
desaparecimento. A importância de retomarmos esse debate e voltarmos aos clássicos, portanto, é tarefa ainda imprescindível para aquele que pretende compreender o universo rural e agrícola, tão complexo, conflituoso e por vezes contraditório. Além do mais, termos reconhecimento de como os próprios clássicos colocaram as questões em debate, levando em consideração o contexto de vida deles, nos permite reflexões sempre atuais de como nós, em nossos próprios contextos, concebemos e analisamos a realidade que nos cerca. Compreender, portanto, a dinâmica da vida social do campesinato e das mudanças agrárias em curso, se coloca aqui como um exercício teórico importante que também (e ainda) os próprios clássicos podem muito contribuir.

\section{Referências}

ABRAMOVAY, Ricardo. De camponeses a agricultores: Paradigmas do Capitalismo Agrário em Questão. Tese (Doutorado em Ciências Sociais). Instituto de Filosofia e Ciências Humanas da Universidade Estadual de Campinas (UNICAMP). Campinas, 1990.

BERNSTEIN, Henry. Dinâmicas de Classe e mudança agrária. São Paulo. Editora Unesp. 2011.

BRANDENBURG, Alfio. Mundo Rural e Ruralidades. Curitiba: Editora da UFPR, 2018.

CARNEIRO, Maria José (Coord.). Ruralidades contemporâneas: modos de viver e pensar o rural na sociedade brasileira. Rio de Janeiro: Mauad X; FAPERJ, 2012.

CHAYANOV, Alexander. Sobre a teoria dos sistemas econômicos não capitalistas. In: SILVA, José Graziano da; STOLCKE, Verena (Org.). A questão Agrária. Editora Brasiliense. São Paulo, 1981.

CHAYANOV, Alexander. La organización de la unidad económica campesina. Ediciones Nueva Visión. Buenos Aires, Argentina. 1974.

ENGELS, Friedrich. A situação da classe trabalhadora na Inglaterra. São Paulo: Boitempo, 2010.

KAUTSKY, Karl. A questão Agrária: a evolução da agricultura na sociedade capitalista. Vol. I, Portucalense Editora, Porto, 1972a. 
KAUTSKY, Karl. A questão Agrária: a evolução da agricultura na sociedade capitalista. Vol. II, Portucalense Editora, Porto, 1972b.

LÊNIN, Vladimir Ilich. O Desenvolvimento do Capitalismo na Rússia: O Processo de Formação do Mercado Interno para a Grande Indústria. São Paulo: Abril Cultural, 1982.

MARX, Karl. O Capital: crítica da economia política: Livro I: o processo da produção do capital; tradução Rubens Enderle, 2. Ed., São Paulo: Boitempo, $2017 a$.

MARX, Karl. O Capital: crítica da econômica política: Livro III: o processo global da produção capitalista; tradução Rubens Enderle; edição de Friedrich Engels, 1. Ed., São Paulo: Boitempo, 2017b.

NETTO, José Paulo. Introdução. In: LENIN, Vladimir Ilich. O Desenvolvimento do Capitalismo na Rússia: O Processo de Formação do Mercado Interno para a Grande Indústria. São Paulo: Abril Cultural, 1982.

PLOEG, Jan Douwe van der. Camponeses e impérios alimentares: lutas por autonomia e sustentabilidade na era da globalização. Porto Alegre: Editora da UFRGS. 2008.

SILVA, José Graziano da; STOLCKE, Verena (Org.). A questão Agrária. Editora Brasiliense. São Paulo, 1981.

WANDERLEY, Maria de Nazareth Baudel. A ruralidade no Brasil moderno. Por un pacto social pelo desenvolvimento rural. En publicacion: ¿Una nueva ruralidad en América Latina?. Norma Giarracca, Consejo Latinoamericano de Ciencias Sociales (CLACSO). Red de Bibliotecas Virtuales de Ciencias Sociales da América Latina y el Caribe de CLACSO. Ciudad Autónoma de Buenos Aires, Argentina. 2001.

WANDERLEY, Maria de Nazareth Baudel. Agricultura Familiar e Campesinato: Rupturas e Continuidades. Aula Inaugural do primeiro semestre a ser ministrada no CPDA/UFRRJ. 2004.

WANDERLEY, Maria de Nazareth Baudel. O Mundo rural como espaço de vida: reflexões sobre a propriedade da terra, agricultura familiar e ruralidade. Porto Alegre: UFRGS, 2009. 